\title{
NUMERICAL ANALYSIS USING CFD METHODS OF FLOWING AROUND TRIMARAN HULL
}

\author{
Matei Cosmin Baciu \\ "Dunarea de Jos" University of Galati, \\ Faculty of Naval Architecture, Galati, \\ Domneasca Street, No. 47, 800008, Romania, \\ E-mail:baciumateicosmin@yahoo.ro

\section{Costel Iulian Mocanu} \\ "Dunarea de Jos" University of Galati, \\ Faculty of Naval Architecture, Galati, \\ Domneasca Street, No. 47, 800008, Romania, \\ E-mail:costel.mocanu@ugal.ro
}

\author{
Liviu Galatanu \\ "Dunarea de Jos" University of Galati, \\ Faculty of Naval Architecture, Galati, \\ Domneasca Street, No. 47, 800008, Romania, \\ E-mail: liviu.galatanu@glo-marine.com

\section{Razvan Bidoae} \\ "Dunarea de Jos" University of Galati, \\ Faculty of Naval Architecture, Galati, \\ Domneasca Street, No. 47, 800008, Romania, \\ E-mail:razvan.bidoae@ugal.ro
}

\begin{abstract}
In order to reduce the pollution caused by the expanding economy, solutions are sought to find new forms of energy instead of the one based on the burning of fossil fuels. In this context, the Nordic countries (Sweden, Denmark, the Netherlands, England, Norway) use the wind as a source of electricity generation. Thus, in the North Sea of the European continent, "windmills" appeared, which, through the generators, are coupled to a system of pale energy production. These complex installations are installed in large winds with strong winds that produce waves with high heights and short periods. Vessels that service these complicated installations must respond to safe sailing requirements for maintenance personnel and transported equipment. Since classical ships do not exactly fit these requirements, they look for forms of hulls that give good behavior to such large ones. In the paper, the Trimaran type ship is approached, using the CFD numerical methods, the shape of the bodies as well as the distance between the bodies so that the ship's behavior meets the safety requirements of the offshore installation.
\end{abstract}

Keywords: ship resistance, numerical analysis, trimaran hull

\section{INTRODUCTION}

Nowadays, the trimaran is a ship that is used in the military and civilan fields. The concept was first developed as a small craft in sports competitions.

It was subsequently applied in the military field due to the fact that it has good stability capabilities, low hydrodynamic resistance and extended deck space.

This paper is based on rescue boat with the following characteristics:

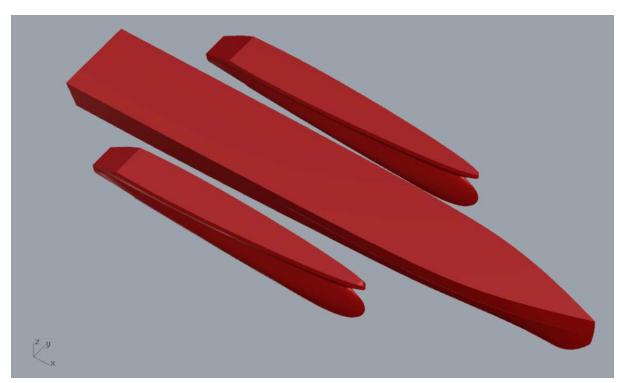

Fig. 1. Trimaran preview 
Table 1. Main dimensions

\begin{tabular}{|c|c|c|}
\hline Length & 21,00 & $\mathrm{~m}$ \\
\hline Beam & 8,00 & $\mathrm{~m}$ \\
\hline Draft & 1,40 & $\mathrm{~m}$ \\
\hline Depth & 2,10 & $\mathrm{~m}$ \\
\hline Speed & 9,00 & $\mathrm{~m} / \mathrm{s}$ \\
\hline Displacement & 52,000 & $\mathrm{t}$ \\
\hline
\end{tabular}

The distance between the main float and the second floats is $3,2 \mathrm{~m}$ :

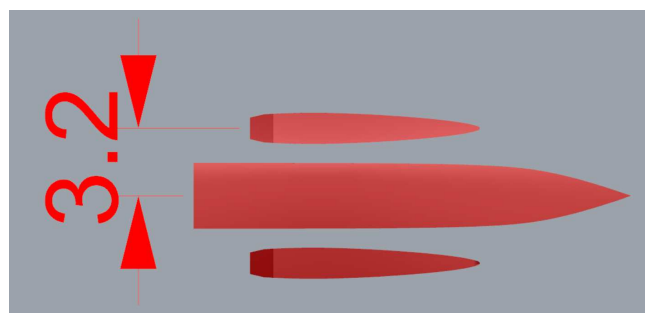

Fig. 3. The distance between the floats

\section{MAIN FLOAT SHAPE}

The main float dimensions:

- $\quad$ Length - $21 \mathrm{~m}$;

- Beam-3,1 m;

- Depth-2,1 m.

The main float is characteristic by:

- 2 knuckles curves;

- V shape in foreward;

- V shape in aft;

- Submerged transom;

- Special propeller area;

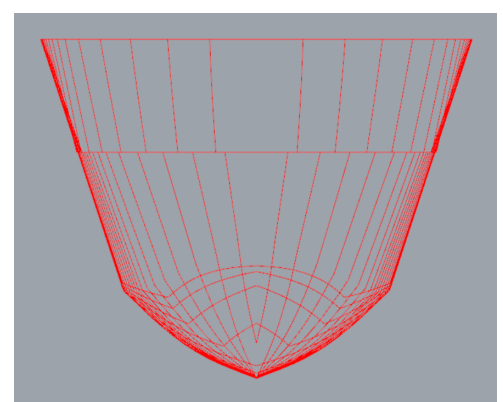

Fig. 2. Sections of main float
The propeller area is characteristic by:

- $\quad 0,7 \mathrm{~m}$ - height;

- $1,2 \mathrm{~m}$ - beam;

- $3,5 \mathrm{~m}$ - length.

The propeller area is to smoothing the wake in propeller disk and to generate space for propeller disk in the aft of the ship.

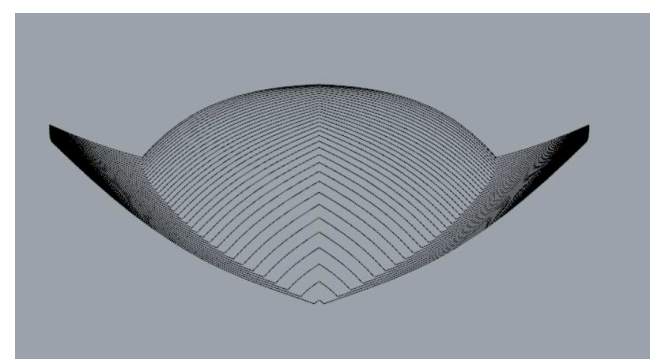

Fig. 3. Sections of propeller area

\section{SECOD FLOAT SHAPE}

The second float dimensions:

- $\quad$ Length - $11 \mathrm{~m}$;

- Beam - 1,5 m;

- Depth $-2,1 \mathrm{~m}$.

The main float is characteristic by:

- 2 knuckles curves;

- Rambow - fore profile;

- V shape in aft;

- Submerged transom;

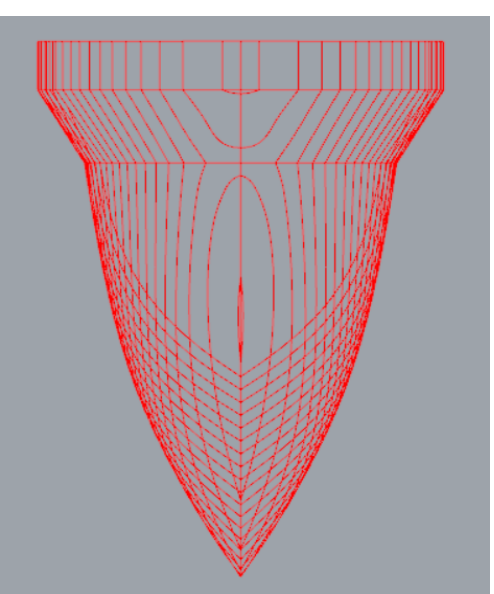

Fig. 3. Sections of second float 


\section{NUMERICAL ANALYSIS}

The numerical analysis has been realised in Numeca: Fine-Marine software. This software has Reynolds Navier Stokes Equation as calculation model.

The used flowing model is SST-Menter that based on Courant number value under 1 .

The used mesh has 4 millions of cells and $\mathrm{Y}+$ value is +40 .

The analysis have been solved in calm water used $9 \mathrm{~m} / \mathrm{s}$ velocity.

The Froude number value is 0,62 and the model is in semi-displacement domain.

\section{FIRST CASE}

In the first case, the distance between the floats fore is $7,3 \mathrm{~m}$.

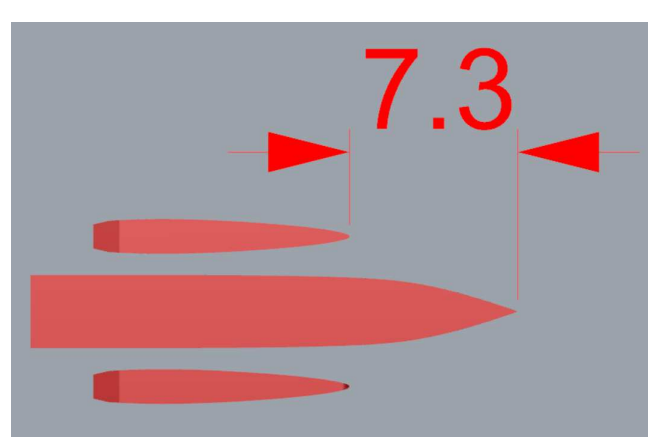

Fig. 4. The distance between the floats fore

The hydrodynamic resistance is 54,55 $\mathrm{kN}$ in 7500 computational cycles.

The appeared phenomena:

- Wave trough in the main float's transom area - 1,15 m (measured from waterline);

- Wave trough in the second float's transom area $-0,65 \mathrm{~m}$ (measured from waterline);

- Wave creast in the main float's fore $-0,6 \mathrm{~m}$ (measured from waterline);

- Wave creast in the second float's fore - 0,85 $\mathrm{m}$ (measured from waterline);

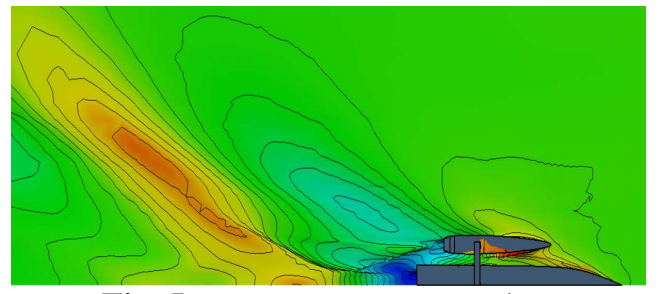

Fig. 5. Wave system - Top view

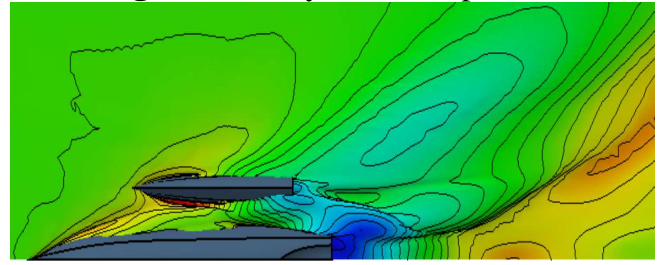

Fig. 6. Wave system - Bottom view

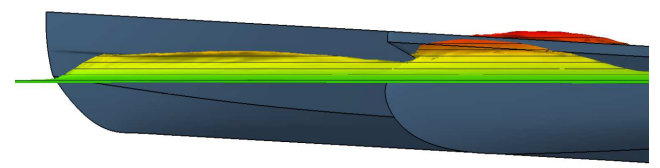

Fig. 7. Wave system - Fore area Longitudinal view

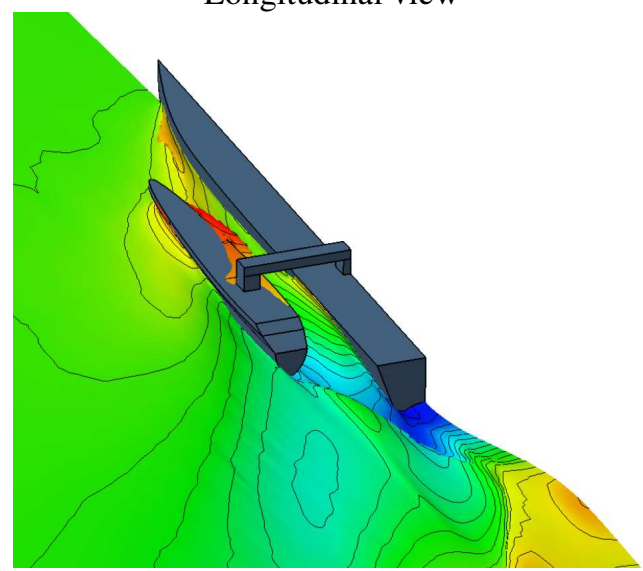

Fig. 8. Wave system - Isometric view

\section{SECOND CASE}

In the second case, the distance between the floats fore is $10 \mathrm{~m}$. 


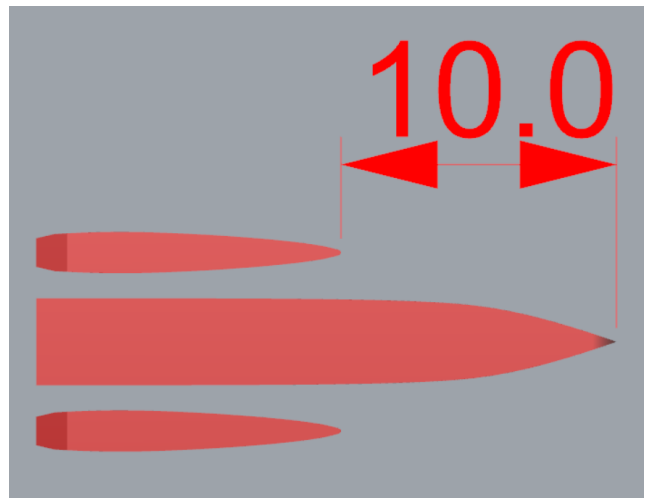

Fig. 9. The distance between the floats fore

The hydrodynamic resistance is 49,26 $\mathrm{kN}$ in 7500 computational cycles.

The appeared phenomena:

- Wave trough in the main float's transom area $-1,15 \mathrm{~m}$ (measured from waterline);

- Wave trough in the second float's transom area $-1 \mathrm{~m}$ (measured from waterline);

- Wave creast in the main float's fore 0,6 $\mathrm{m}$ (measured from waterline);

- Wave creast in the second float's fore 0,6 m (measured from waterline);

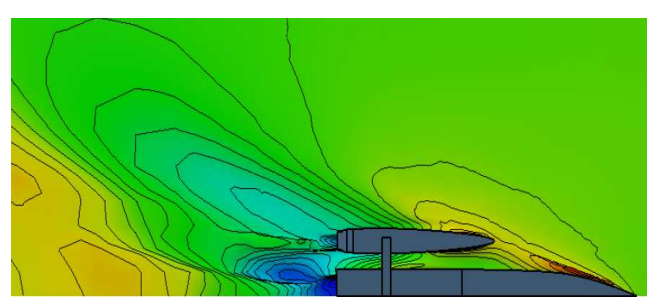

Fig. 10. Wave system - Top view

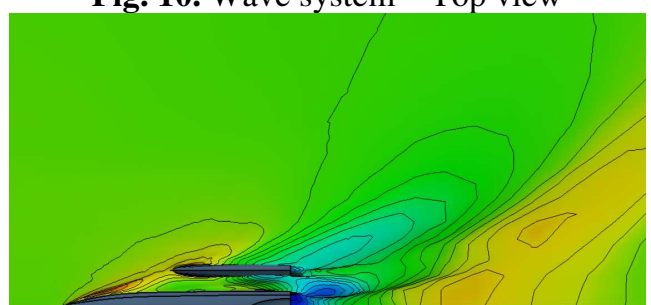

Fig. 11. Wave system - Bottom view

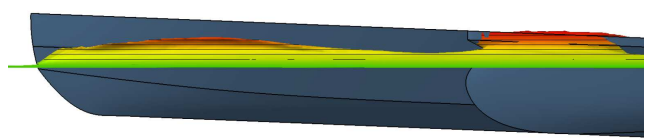

Fig. 12. Wave system - Fore area Longitudinal view

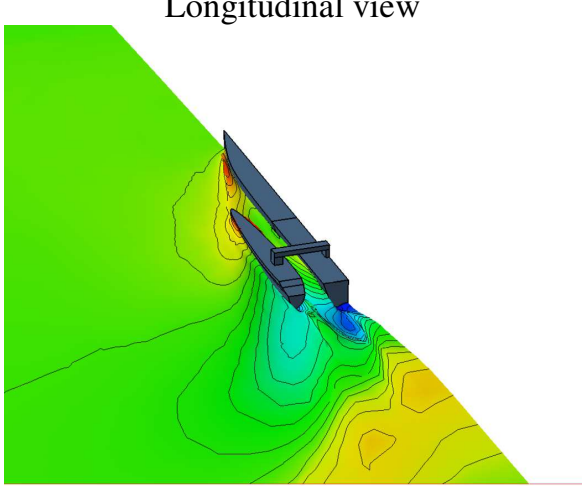

Fig. 13. Wave system - Isometric view

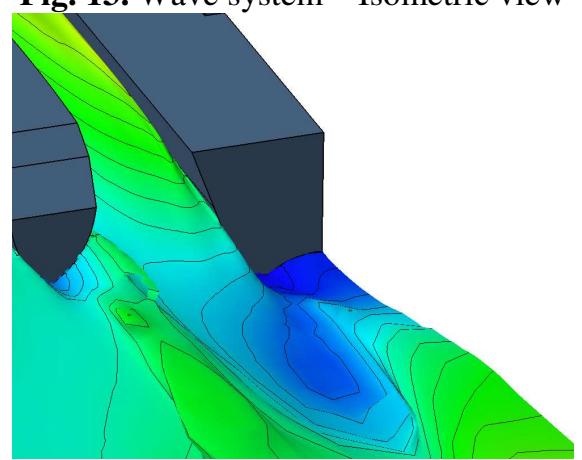

Fig. 14. Wave system - Isometric view

\section{CONCLUSION}

The wave system of the main float are composed with the wave system of the second float, and the hydrodynamic resistance decrease by increasing the distance between the floats fore.

The move of the position of the second float generates a reducing of hydrodynamic resistance with $10 \%$ (from $55,44 \mathrm{kN}$ to $49,26 \mathrm{kN}$ ).

The specific of the propeller area is the dissipation streamline that maintain the propeller underwater in all conditions.

\section{REFERENCES}

[1]. Ecole Centrale de Nantes: "ISIS-CFD", Support book from Numeca: Fine-Marine

Paper received on December $31^{\text {th }}$, 2018 